Bull. Chem. Soc. Ethiop. 2014, 28(1), 101-110.

Printed in Ethiopia

ISSN 1011-3924

DOI: http://dx.doi.org/10.4314/bcse.v28i1.12

(C) 2014 Chemical Society of Ethiopia

\title{
INFLUENCE OF THE SUBSTITUTION ON THE ELECTRONIC PROPERTIES OF PERYLENE-3,4:9,10-BIS(DICARBOXIMIDES): DENSITY FUNCTIONAL THEORY STUDY
}

\author{
Ahmad Irfan* \\ Department of Chemistry, Faculty of Science, King Khalid University, Abha 61413, P.O. Box \\ 9004, Saudi Arabia
}

(Received December 26, 2012; revised June 27, 2013)

\begin{abstract}
Geometries of the substituted perylene-3,4:9,10-bis(dicarboximides) (PDI) and their radical anions have been optimized at the B3LYP/6-31G** level of theory. The adiabatic and vertical electron affinities have been computed at the B3LYP/6-31+G*//B3LYP/6-31G** level. Substitution of the PDI with $\mathrm{COOCF}_{3}$ reduces the energies of both the highest occupied molecular orbital (HOMO) and lowest unoccupied molecular orbital (LUMO) with the only exception of PDI4 derivative. Calculations predict a decrease in the electron injection barrier in the materials based on the proposed compounds comparing to the parent PDI. Taking into account the calculated electron affinities (EA), the air stability and ambipolar behavior of the materials under study can be expected.
\end{abstract}

KEY WORDS: Organic field effect transistors, Highest occupied molecular orbitals, Lowest unoccupied molecular orbitals, Electron affinity, Air stability

\section{INTRODUCTION}

In recent years, organic semiconductors have attracted considerable attention because of their potential for creating low-cost, portable electronic and optoelectronic devices such as organic light emitting diodes (OLEDs), organic field effect transistors (OFETs), flexible displays, and sensors [1-3]. Some small molecule compounds with a large $\pi$-conjugated ring structure have been demonstrated as good semiconductors [4-7]. All of these compounds show good crystallinity. The higher performance found in single crystal OFETs compared to thin-film OFETs is related to the high molecular ordering and the absence of grain boundaries in the crystals [8]. Recently, a number of studies have been carried out to improve the performance and to design efficient OFETs materials [9-11].

In general, n-type semiconductors should possess low LUMO energy which in turn results in large electron affinity which should actually be close to the work function of the source-drain electrodes, yielding smaller charge injection barrier for electron to ensure the effective charge injection from the source electrode. Although remarkable progress has recently been made in developing new $n$-channel organic semiconductors, only a few $n$-channel OFETs can operate under ambient conditions because of unstable radical anions [12]. Perylene n-type semiconductors have been investigated by Marks et al. [13]. Moreover, Jones et al. studied the effect of substituents Perylene based materials [14, 15]. Naphthalene-1,4:5,8-bis(dicarboximides) (NDI) and perylene-3,4:9,10-bis(dicarboximides) (PDI) derivatives are the most commonly used air-stable $n$-channel semiconductors because of their high EAs that stabilize their radical anions under ambient conditions [16-26].

Marks and Takimiya et al., respectively, showed that 2,8-di-4,4'-didodecyl-2,2'-bithiopheneindeno[1,2-b]fluorene-6,12-dimalononitrile (BTIFDMT) and 5,5"-bis(dicyanomethylene)-5,5"dihydro-2,1';3',2"-diselenyl-5',5'-bis(hexyloxymethyl) cyclopenta[c]thiophene (DCMST) can be applied in air stable ambipolar (the flow of electron and hole transport in semiconductor is

*Corresponding author. E-mail: irfaahmad@gmail.com 
nearly equal) OFETs due to substitution of the nitrile group [27-28]. The oligothiophenes bearing carbonyl groups have been exploited as $n$-type OFET materials [29-35], where it was explained that trifluoroacetyl groups at the terminal positions of the $\pi$-conjugated backbone is effective in lowering the LUMO energy level and arranging the molecules in crystals [36].

Chang et al. calculated adiabatic EA to explain the air stability and the threshold value was predicted to be ca. $2.797 \mathrm{eV}$ [37] at the B3LYP/6-31+G*//B3LYP/6-31G** level. In the present study, our aim is to enhance the air stability. Thus we have substituted strong electron withdrawing group $\left(-\mathrm{COOCF}_{3}\right)$ at different positions of PDI derivatives (see Figure 1). We have shed light on the highest occupied molecular orbitals (HOMOs) and lowest unoccupied molecular orbitals (LUMOs), energy gaps, and electron affinities (EA). On the basis of EA, we have explained the air stability of new designed PDI derivatives and electron transfer behavior. The influence of position and number of the substituents on the charge transfer and air stability has been also investigated.
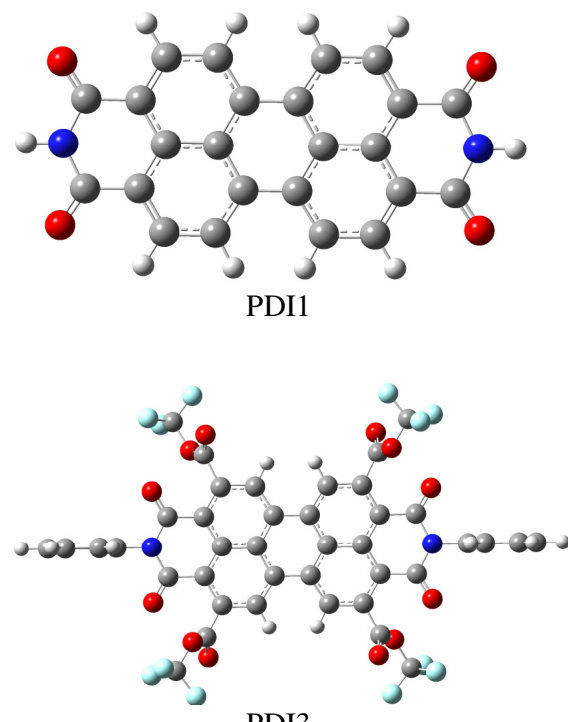

PDI3

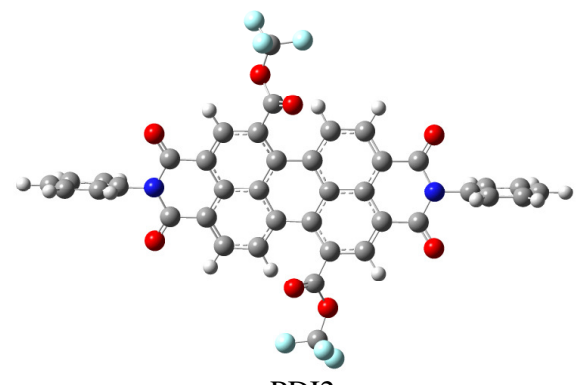

PDI2

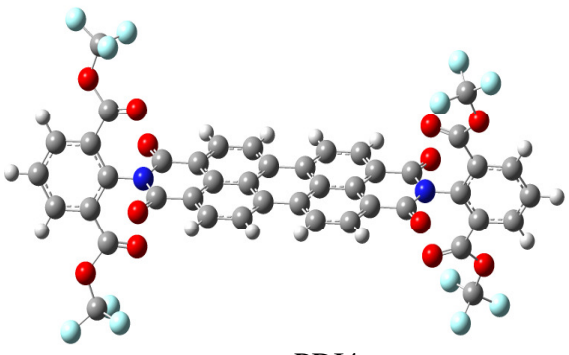

PDI4

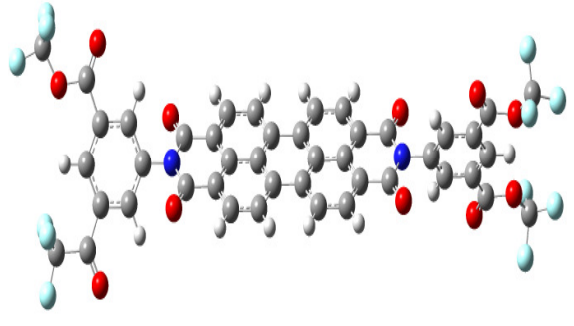

PDI5

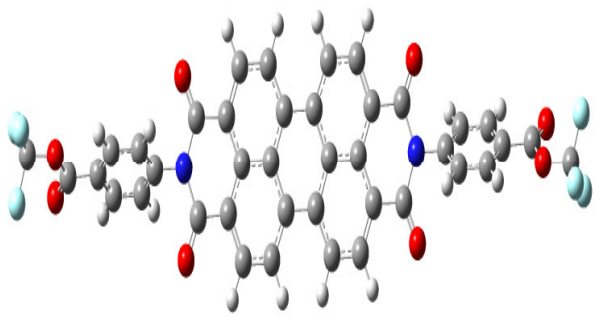

PDI6 


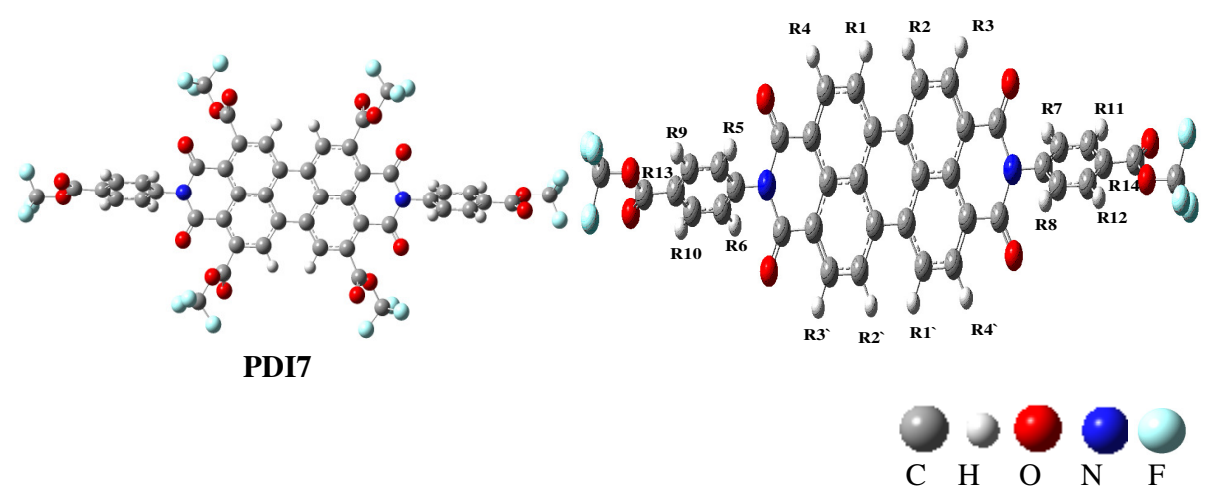

Figure 1. The structures of the investigated derivatives of perylene-3,4:9,10-bis(dicarboximide) (PDI1-PDI7) and numbering scheme used in the present study.

\section{COMPUTATIONAL DETAILS}

The ground state geometries have been calculated using density functional theory (DFT) with Gaussian09 package [38]. The DFT [39] was treated according to Becke's three parameter gradient-corrected exchange potential and the Lee-Yang-Parr gradient-corrected correlation potential (B3LYP) [40, 41] by using 6-31G** basis sets [42] for neutral and anionic species. Chang computed the EAs of PDI compounds at B3LYP/6-31+G*//B3LYP/6-31G** level of theory which are in good agreement with experimental and already computed data [37]. The EAs (uncorrected with zero-point vibrational energy (ZPE)) of naphthalene to pentacene, chrysene, pyrene, two benzopyrenes, and fluoranthene compounds have been computed at B3LYP/6-31+G* level of theory deviate from experimentally determined EAs no more than 0.1 $\mathrm{eV}$ [43]. It has been reported that the B3LYP/6-31+G** level is a reliable theory level to reproduce the EAs. Chao et al. showed that the difference of EAs between B3LYP/6-31+G* and B3LYP/6-31+G*//B3LYP/6-31G** level of theories is within $0.002 \mathrm{eV}$ [43b]. The EA differences between the B3LYP/6-31+G*//B3LYP/6-31G** and B3LYP/6-31+G* are negligible. Thus we have applied the same level of theory (B3LYP/6-31+G*//B3LYP/6-31G**) to investigate the EAs (neutral and anion geometries have been optimized at the same level of theory) of new designed derivatives of PDI.

\section{RESULTS AND DISCUSSION}

\section{Electronic structure}

Table 1 presents the energies of HOMO $\left(E_{\mathrm{HOMO}}\right)$ and LUMO $\left(E_{\mathrm{LUMO}}\right)$, HOMO-LUMO energy gap $\left(E_{\mathrm{g}}\right)$, and EAs of PDI derivatives. The substitution of PDI1 with $\mathrm{COOCF}_{3}$ at R1 and R1' positions (PDI2) lowers the $E_{\mathrm{HOMO}}$ and $E_{\mathrm{LumO}}$ by 0.34 and $0.38 \mathrm{eV}$, respectively. The substitution of DPI1 with COOCF3 at R3, R3', R4 and R4' positions (PDI3) lowers the $E_{\mathrm{HOMO}}$ and $E_{\mathrm{LUMO}}$ by 0.76 and $0.74 \mathrm{eV}$, respectively. Similar to the previous cases, the substitution of PDI1 at R9, R10, R11 and R12 positions (PDI5) lowers both the $E_{\mathrm{HOMO}}$ and $E_{\mathrm{LUMO}}$ by $0.33 \mathrm{eV}$, and by 0.21 and $0.19 \mathrm{eV}$, respectively, upon substitution at R13 and R14 positions (PDI6). The most pronounced reduction of the energies of the $E_{\mathrm{HOMO}}$ and $E_{\mathrm{LUMO}}$ (by 1.05 and $1.04 \mathrm{eV}$, respectively) was predicted upon the PDI1 substitution at positions R3, R3', R4, R4' R13 
(PDI7). On the contrary, the substitution at R5, R6, R7 and R8 positions (PDI4) leads to slightly higher values of $E_{\text {Номо }}$ and $E_{\mathrm{LUMO}}$ (by 0.17 and $0.16 \mathrm{eV}$, respectively).

As can be expected, Table 1 shows that the effect of substitution on the HOMO and LUMO energies depends on the number of electron withdrawing substituents. With the only exception of PDI4, the substitution with electron withdrawing groups at different positions leads to lower HOMO and LUMO energies. From the results presented in Table 1, a general trend in the increase of $E_{\mathrm{HOMO}}$ and $E_{\mathrm{LUMO}}$ is seen: PDI7 < PDI3 < PDI $<$ PDI5 < PDI6 < PDI $1<$ PDI4. On the other hand, the HOMO-LUMO energy gap (Egap) is almost independent of substitution.

Table 1. The energies of the HOMO ( $\left.E_{\text {Hомо }}\right)$ and LUMO ( $\left.E_{\mathrm{LUMO}}\right)$, HOMO-LUMO energy gaps $\left(E_{\mathrm{g}}\right)$, vertical electron affinities $\left(\mathrm{EA}^{v}\right)$, and adiabatic electron affinities $\left(\mathrm{EA}^{a}\right)$ of compounds PDI1-PDI7 calculated at B3LYP/6-31G** level of theory (all values are in $\mathrm{eV}$ ).

\begin{tabular}{|c|c|c|c|c|c|}
\hline Systems & $E_{\text {HOMO }}$ & $E_{\text {LUMO }}$ & $E_{g}$ & $E A^{v}$ & $E A^{a}$ \\
\hline PDI1 & -6.11 & -3.58 & 2.53 & $-2.27(2.64)$ & $-2.40(2.78)$ \\
\hline PDI2 & -6.45 & -3.96 & 2.49 & $-2.79(3.20)$ & $-3.03(3.46)$ \\
\hline PDI3 & -6.87 & -4.32 & 2.55 & $-3.20(3.57)$ & $-3.40(3.72)$ \\
\hline PDI4 & -5.94 & -3.42 & 2.52 & $-2.25(2.66)$ & $-2.49(2.89)$ \\
\hline PDI5 & -6.44 & -3.91 & 2.53 & $-2.70(3.12)$ & $-2.91(3.33)$ \\
\hline PDI6 & -6.32 & -3.79 & 2.53 & $-2.60(2.98)$ & $-2.78(3.14)$ \\
\hline PDI7 & -7.16 & -4.62 & 2.54 & $-3.51(3.94)$ & $-3.73(4.09)$ \\
\hline
\end{tabular}

The values in parentheses have been computed at B3LYP/6-31+G*//B3LYP/6-31G** level of theory

Figure 2 displays the HOMOs and LUMOs of compounds under study. The HOMO of the PDI1 is delocalized over the perylene fragment and the oxygens also participate in the formation of the HOMO. The LUMO is also delocalized over entire perylene fragment. The oxygens of the PDI1 also participate in the formation of LUMO. It is seen from Figure 2 that HOMOs and LUMOs of all compounds under study (PDI2-PDI7) are delocalized over the PDI unit and both aryl substituents do not participate in the formation of HOMOs and LUMOs.

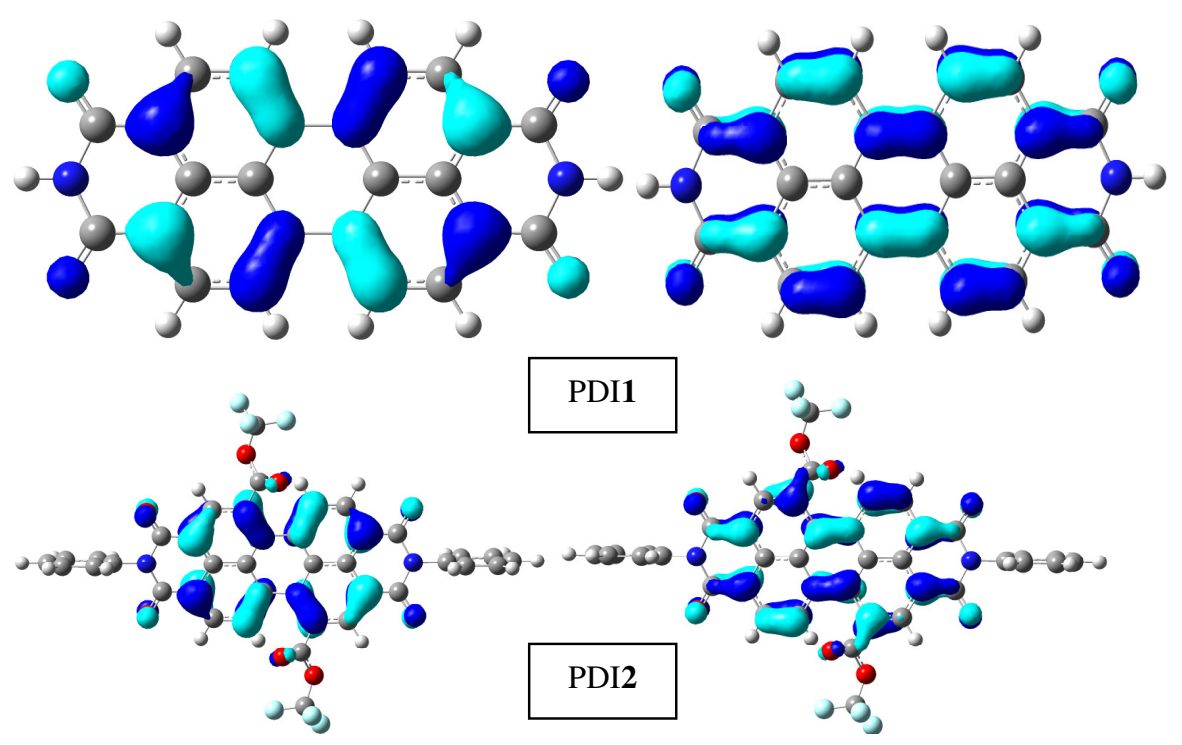

Bull. Chem. Soc. Ethiop. 2014, 28(1) 
Influence of substitution on electronic properties of perylene-3,4:9,10-bis(dicarboximides) 105
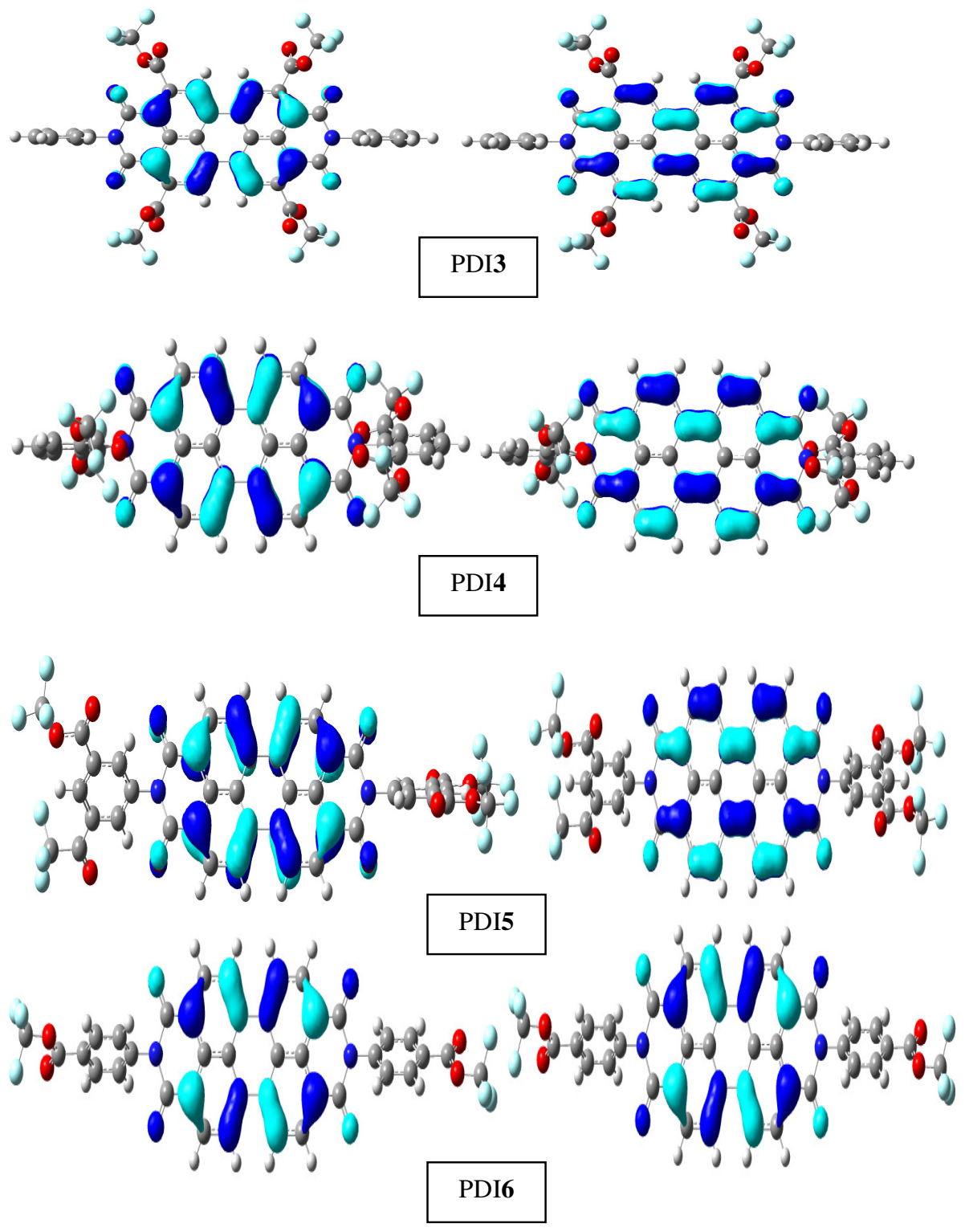


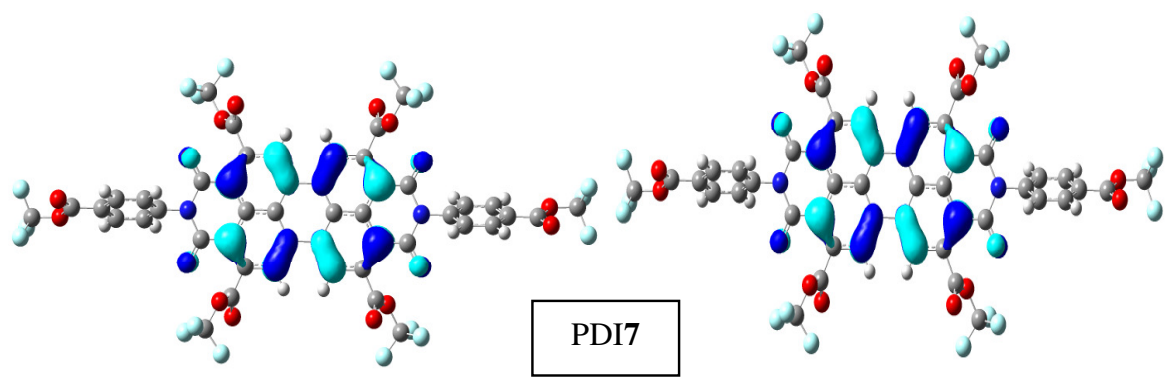

HOMO

LUMO

Figure 2. The HOMO and LUMO distribution pattern of PDI1-PDI7.

The Newman et al. pointed out that the materials with electron affinity (3.0 to $4.0 \mathrm{eV}$ ) would be good $n$-type materials for OFETs due to the efficient electron injection from common gold electrode, ca. $5.1 \mathrm{eV}$ and enough ambient stability [44]. The work function of aluminum is -5.1 $\mathrm{eV}$ and the LUMO energy level of PDI1 is $-3.58 \mathrm{eV}$ (see Table 1), the injection energy is around $1.52 \mathrm{eV}(=-3.58-(-5.1))$ from the PDI1 to Al electrode. Therefore, it is necessary to lower the LUMO level to enhance the electron injection ability. From Table 1 it can be found that by substitution with COOCF3 at different positions make the LUMO energy levels lower predicting the reduction of the injection barrier, i.e., 1.14, 0.78, 1.19, 1.31, $0.48 \mathrm{eV}$ for PDI2, PDI3, PDI5, PDI6 and PDI7, respectively.

\section{Electron affinities}

PDI1 and its derivatives have promising potential for $n$-type organic semiconductors due to their appropriate $\mathrm{EA}^{a}$. The $\mathrm{EA}^{a}$ is actually important when determining air stability of materials. Previous studies have shown that substitution of electron withdrawing groups for small band gap materials is an effective strategy for synthesizing air-stable ambipolar OFET materials [45, 46]. As we explained above that $\mathrm{EA}^{\mathrm{a}}$ more than $2.797 \mathrm{eV}$ mostly afford air-stable OFET devices and that those with $\mathrm{EA}^{\mathrm{a}}$ smaller than $2.797 \mathrm{eV}$ mostly afford air-unstable ones. The results presented in Table 1 and Figure 3 indicates that substituent positions can have different impacts on the EA values of materials. Chen and Bao et al. have reported electrical characterization of a series of N-phenylated PDIs with different number of fluorine atoms on the phenyl substituents. In their study, only the unfluorinated PDIsPh was deemed air-unstable when measured immediately after air exposure [47].

Here we have discussed the EA ${ }^{\text {a }}$ at B3LYP/6-31+G*//B3LYP/6-31G** level of theory. By substituting the $-\mathrm{COOCF}_{3}$ at $\mathrm{R} 1$ and $\mathrm{R} 1$ ' (PDI2) leads the EA to $3.46 \mathrm{eV}$ which is $0.68 \mathrm{eV}$ higher than the EA of PDI1. The substitution of $-\mathrm{COOCF}_{3}$ at R3, R3', R4 and R4' positions (PDI3) further improve the $\mathrm{EA}^{\mathrm{a}}$ to $3.72 \mathrm{eV}$. The $-\mathrm{COOCF}_{3}$ at $\mathrm{R} 5, \mathrm{R} 6, \mathrm{R} 7$ and $\mathrm{R} 8$ positions (PDI4) leads to higher the $\mathrm{EA}^{\mathrm{a}}$ to $2.89 \mathrm{eV}$. The $-\mathrm{COOCF}_{3}$ at $\mathrm{R} 9, \mathrm{R} 10, \mathrm{R} 11$ and $\mathrm{R} 12$ positions (PDI5) escorts the $\mathrm{EA}^{\mathrm{a}}$ to $3.33 \mathrm{eV}$. It can be seen than substitution of $-\mathrm{COOCF}_{3}$ at four positions within the core is more effective one while the substitution at peripheral phenyl rings is not so efficient especially when the substitution at peripheral phenyl is near to the core (PDI4). While the substitution of $-\mathrm{COOCF}_{3}$ at outer peripheral phenyl hydrogens (PDI5) is proficient. The substitution of $-\mathrm{COOCF}_{3}$ at R13 and R14 (PDI6) is leading $\mathrm{EA}^{\mathrm{a}}$ to $3.14 \mathrm{eV}$. The substitution of $-\mathrm{COOCF}_{3}$ at R3, R3', R4, R4' R13 and R14 (PDI7) direct EA $4.09 \mathrm{eV}$ which is 
the highest one. It is might be due to the reason that four $-\mathrm{COOCF}_{3}$ groups have been substituted within the core and two groups are at terminal of the peripheral phenyl rings. The $\mathrm{EA}^{\mathrm{a}}$ values of PDI2-PDI7 meet the needed energy levels for designing air-stable ambipolar OFET materials. The results presented in Table 1 showed that $-\mathrm{COOCF}_{3}$ group substitution can effectively decrease the injection barrier for electron and therefore it would be potential ambipolar semiconductor materials. Thus before going to synthesize new n-channel materials, it would be better to compute the EA at B3LYP/6-31+G*//B3LYP/6-31G** level of theory. The new designed materials having $\mathrm{EA}^{\mathrm{a}}$ close or larger than $2.8 \mathrm{eV}$ can be synthesized which would have more probability to be air stable.

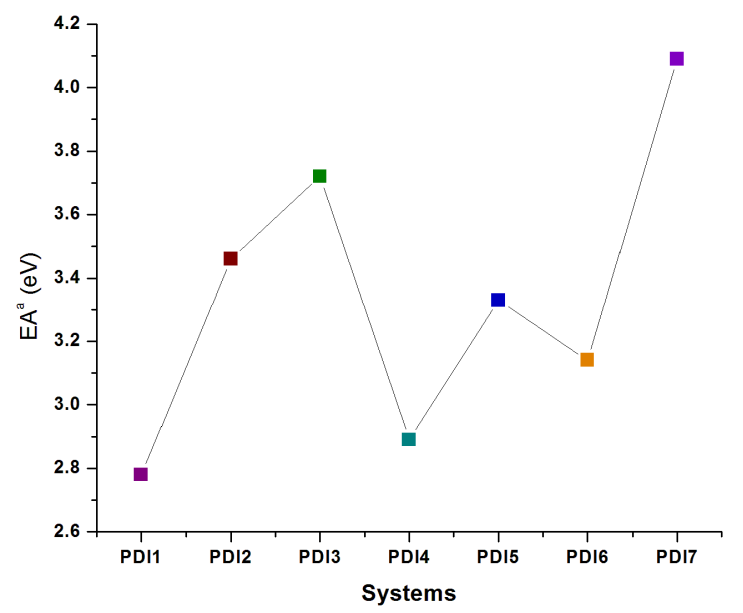

Figure 3. The $\mathrm{EA}^{\mathrm{a}}$ of studied systems computed at B3LYP/6-31+G*//B3LYP/6-31G** level of theory.

\section{CONCLUSIONS}

The substitution of PDI with strong electron withdrawing group lowers the $E_{\text {LUMO }}$ except for PDI4. The HOMO and LUMO are delocalized on whole of the PDI core, terminal oxygens of the PDI also participate in the formation of HOMO. No participation has been observed in the formation of HOMOs and LUMOs for aryl and electron withdrawing group. The electron injection barrier for PDI2, PDI3, PDI5, PDI6 and PDI7 would be smaller than the parent molecule which revealed higher electron transport. The electron affinity of new designed materials is more than $2.797 \mathrm{eV}$ afford air-stable OFET devices. The EA ${ }^{\mathrm{a}}$ values of PDI2-PDI7 meet the needed energy levels for designing air-stable ambipolar OFET materials. Finally, it would be better to compute the $\mathrm{EA}^{\mathrm{a}}$ before synthesizing new n-channel materials. The new designed materials having $\mathrm{EA}^{\mathrm{a}}$ close or larger than $2.8 \mathrm{eV}$ can be synthesized which would have more probability to be air stable.

\section{ACKNOWLEDGEMENTS}

Author is thankful to King Khalid University for the support and facilities to carry out the research work. 


\section{REFERENCES}

1. Coropceanu, V.; Cornil, J.; Filho, D.A.d.S.; Olivier, Y.; Silbey, R.; Bre'das, J.-L. Chem. Rev. 2007, 107, 926.

2. Anthony, J.E. Chem. Rev. 2006, 106, 5028.

3. Bendikov, M.; Wudl, F.; Perepichka, D.F. Chem. Rev. 2004, 104, 4891.

4. Bao, Z.; Lovinger, A.J.; Dodabalapur, A. Adv. Mater. 1997, 9, 42.

5. Klauk, H.; Halik, M.; Zschieschang, U.; Schmid, G.; Radlik, W.; Weber, W. J. Appl. Phys. 2002, 92, 5259.

6. Takeya, J.; Yamagishi, M.; Tominari, Y.; Hirahara, R.; Nakazawa, Y.; Nishikawa, T.; Kawase, T.; Shimoda, T.; Ogawa, S. Appl. Phys. Lett. 2007, 90, 102120.

7. Aramaki, S.; Ohno, A. Japanese Patent Application 2006; Publication No. JP2006-165533

8. Warta, W.; Karl, N. Phys. Rev. B 1985, 32, 1172.

9. Kou, M.Y.; Chen, H.Y.; Chao, I. Chem. Eur. J. 2007, 13, 4750.

10. Chen, H.Y.; Chao, I. Chem. Phys. Lett. 2005, 401, 539.

11. Winkler, M.; Houk, K.N. J. Am. Chem. Soc. 2007, 129, 1805.

12. Deng, W.Q.; Goddard, W.A. J. Phys. Chem. B 2004, 108, 8614.

13. Marks, T.J.; Wasielewski, M.R.; Facchetti, A.; Ahrens, M.J.; Jones, B.A.; Yoon, M.-H. US Patent 2005/0176970 A1.

14. Ahrens, M.J.; Fuller, M.J.; Wasielewski, M.R. Chem. Mater. 2003, 15, 2684.

15. Jones, B.A.; Ahrens, M.J.; Yoon, M.-H.; Facchetti, A.; Marks, T.J.; Wasielewski, M.R. Angew. Chem. Int. Ed. 2004, 43, 6363.

16. Schmidt, R.; Oh, J.H.; Sun, Y.S.; Deppisch, M.; Krause, A.M.; Radacki, K.; Braunschweig, H.; Könemann, M.; Erk, P.; Bao, Z.; Wu"rthner, F. J. Am. Chem. Soc. 2009, 131, 6215.

17. Katz, H.E.; Lovinger, A.J.; Johnson, J.; Kloc, C.; Siegrist, T.; Li, W.; Lin, Y.Y.; Dodabalapur, A. Nature 2000, 404, 478.

18. Ling, M.M.; Erk, P.; Gomez, M.; Koenemann, M.; Locklin, J.; Bao, Z. Adv. Mater. 2007, $19,1123$.

19. Jones, B.A.; Ahrens, M.J.; Yoon, M.H.; Facchetti, A.; Marks, T.J.; Wasielewski, M.R. Angew. Chem., Int. Ed. 2004, 43, 6363.

20. Tatemichi, S.; Ichikawa, M.; Koyama, T. Appl. Phys. Lett. 2006, 89, 112108.

21. Chen, H.Z.; Ling, M.M.; Mo, X.; Shi, M.M.; Wang, M.; Bao, Z. Chem. Mater. 2007, 19, 816.

22. Schmidt, R.; Ling, M.M.; Oh, J.H.; Winkler, M.; Ko“nemann, M.; Bao, Z.; Wu“rthner, F. Adv. Mater. 2007, 19, 3692.

23. See, K.C.; Landis, C.; Sarjeant, A.; Katz, H.E. Chem. Mater. 2008, 20, 3609.

24. Jung, B.J.; Sun, J.; Lee, T.; Sarjeant, A.; Katz, H.E. Chem. Mater. 2009, $21,94$.

25. Jones, B.A.; Facchetti, A.; Wasielewski, M.R.; Marks, T.J. J. Am. Chem. Soc. 2007, 129, 15259.

26. Chang, Y.C.; Kuo, M.Y.; Chen, C.P.; Lu, H.F.; Chao, I. J. Phys. Chem. C 2010, 114, 11595.

27. Usta, H.; Risko, C.; Wang, Z.; Huang, H.; Deliomeroglu, M.K.; Zhukhovitskiy, A.; Facchetti, A.; Marks, T.J. J. Am. Chem. Soc. 2009, 131, 5586.

28. Handa, S.; Miyazaki, E.; Takimiya, K. Chem. Commun. 2009, 3919.

29. Yoon, M.H.; DiBenedetto, S.A.; Facchetti, A.; Marks, T.J. J. Am. Chem. Soc. 2005, 127, 1348.

30. Letizia, J.A.; Facchetti, A.; Stern, C.L.; Ratner, M.A.; Marks, T.J. J. Am. Chem. Soc. 2005, $127,13476$.

31. Yoon, M.-H.; DiBenedetto, S. A.; Russel, M.T.; Facchetti, A.; Marks, T.J. Chem. Mater. 2007, 19, 4864. 
Influence of substitution on electronic properties of perylene-3,4:9,10-bis(dicarboximides) 109

32. Cai, X.; Gerlach, C.P.; Frisbie, C.D. J. Phys. Chem. C. 2007, 111, 452.

33. Ie, Y.; Umemoto, Y.; Okabe, M.; Kusunoki, T.; Nakayama, K.-i.; Pu, Y.-J.; Kido, J.; Tada, H.; Aso, Y. Org. Lett. 2008, 10, 833.

34. Lee, T.; Landis, C.A.; Dhar, B.M.; Jung, B.J.; Sun, J.; Sarjeant, A.; Lee, H.-J.; Katz, H.E. J. Am. Chem. Soc. 2009, 131, 1692.

35. Ie, Y.; Okabe, M.; Umemoto, Y.; Tada, H.; Aso, Y. Chem. Lett. 2009, 38, 460.

36. Ie, Y.; Nitani, M.; Aso, Y. Chem. Lett. 2007, 36, 1326.

37. Chang, Y.-C.; Kuo, M.-Y.; Chen, C.-P.; Lu, H.-F.; Chao, I. J. Phys. Chem. C 2010, 114, 11595.

38. Frisch, M.J.; Trucks, G.W.; Schlegel, H.B.; Scuseria, G.E.; Robb, M.A.; Cheeseman, J.R.; Scalmani, G.; Barone, V.; Mennucci, B.; Petersson, G.A.; Nakatsuji, H.; Caricato, M.; Li, X.; Hratchian, H.P.; Izmaylov, A.F.; Bloino, J.; Zheng, G.; Sonnenberg, J.L.; Hada, M.; Ehara, M.; Toyota, K.; Fukuda, R.; Hasegawa, J.; Ishida, M.; Nakajima, T.; Honda, Y.; Kitao, O.; Nakai, H.; Vreven, T.; Montgomery, J.A., Jr.; Peralta, J.E.; Ogliaro, F.; Bearpark, M.; Heyd, J.J.; Brothers, E.; Kudin, K.N.; Staroverov, V.N.; Kobayashi, R.; Normand, J.; Raghavachari, K.; Rendell, A.; Burant, J.C.; Iyengar, S.S.; Tomasi, J.; Cossi, M.; Rega, N.; Millam, N.J.; Klene, M.; Knox, J.E.; Cross, J.B.; Bakken, V.; Adamo, C.; Jaramillo, J.; Gomperts, R.; Stratmann, R.E.; Yazyev, O.; Austin, A.J.; Cammi, R.; Pomelli, C.; Ochterski, J.W.; Martin, R.L.; Morokuma, K.; Zakrzewski, V.G.; Voth, G.A.; Salvador, P.; Dannenberg, J.J.; Dapprich, S.; Daniels, A.D.; Farkas, Ö.; Foresman, J.B.; Ortiz, J.V.; Cioslowski, J.; Fox, D.J. Gaussian 09, Revision A.1; Gaussian, Inc.: Wallingford, CT, 2009.

39. Al-Sehemi, A.G.; Irfan, A.; Fouda, A.M. Spectrochim. Acta Part A: Mol. Biomol. Spectros. 2013, 111, 223. (b) Irfan, A.; Al-Sehemi, A.G.; Kalam, A. J. Mol. Struc. 2013, http://dx.doi.org/10.1016/j.molstruc.2013.06.023. (c) Irfan, A.; Al-Sehemi, A.G.; Al-Assiri, M.S. J. Mol. Graphics and Model. 2013, http://dx.doi.org/10.1016/j.jmgm.2013.06.003. (d) Irfan, A.; Cui, R.; Zhang, J.; Nadeem, M. Australian J. Chem. 2010, 63, 1283. (e) Irfan, A.; Al-Sehemi, A.G.; Muhammad, S.; Zhang J. Australian J. Chem. 2011, 64, 1587. (f) Irfan, A.; Cui, R.; Zhang, J.; J. Mol. Struc. (TheoChem) 2010, 956, 61. (g) Irfan, A.; Al-Sehemi, A.G. J. Saudi Chem. Soc. 2011, http://dx.doi.org/10.1016/j.jscs.2011.11.006. (h) AlSehemi, A.G.; Irfan, A.; El-Agrody, A.M. J. Mol. Struc. 2012, 1018, 171. (i) Irfan, A.; AlSehemi, A.G.; J. Saudi Chem. Soc. 2011, http://dx.doi.org/10.1016/j.jscs.2012.03.005. (j) Irfan, A.; Al-Sehemi, A.G.; Asiri, A.M. J. Theor. Comp. Chem. 2012, 11, 631. (k) Irfan, A.; Jin, R.; Al-Sehemi, A.G.; Asiri, Spectrochim. Acta Part A: Mol. Biomol. Spectros. 2013, 110, 60. (1) Irfan, A.; Cui, R.; Zhang, J. Chem. Phys. 2009, 358, 25. (m) Irfan, A.; AlSehemi, A.G.; Asiri, A.M.; Nadeem, M.; Alamry K.A. Comput. Theor. Chem. 2011, 977, 9. (n) Irfan, A.; Aftab, H.; Al-Sehemi, A.G. J. Saudi Chem. Soc. 2011, http://dx.doi.org/10.1016/j.jscs.2011.11.013. (o) Irfan, A.; Ijaz, F.; Al-Sehemi, A.G.; Asiri, A.M. J. Comput. Electron. 2012, 11, 374. (p) Irfan, A.; Hina, N.; Al-Sehemi, A.G.; Asiri, A.M. J. Mol. Model. 2012, 18, 4199. (q) Irfan, A.; Al-Sehemi, A.G.; Asiri, A.M. J. Mol. Model. 2012, 18, 3609. (r) Al-Sehemi, A.G.; Irfan, A.; Asiri, A.M.; Ammar, Y.A. J. Mol. Struc. 2012, 1019, 130. (s) Al-Sehemi, A.G.; Irfan, A.; Asiri, A.M. Theor. Chem. Acc. 2012, 131, 1199. (t) Irfan, A.; Zhang, J.; Chang, Y. Theor. Chem. Acc. 2010, 127, 587. (u) Irfan, A.; Al-Sehemi, A.G. J. Mol. Model. 2012, 18, 4893. (v) Irfan, A.; Cui, R.; Zhang, J. J. Mol. Struc. (TheoChem) 2008, 850, 79. (w) Irfan, A.; Zhang, J.; Chang, Y. Chem. Phys. Lett. 2009, 483, 143. (x) Al-Sehemi, A.G.; Irfan, A.; Asiri, A.M.; Ammar, Y.A. Spectrochim. Acta Part A: Mol. Biomol. Spectros. 2012, 91, 239. (y) Al-Sehemi, A.G.; Al-Melfi, M.A.M.; Irfan, A. Struc. Chem. 2013, 24, 499. (z) Al-Sehemi, A.G.; Al-Amri, R.S.A.; Irfan, A. Acta Phys. Chim. Sin. 2013, 29, 55. 
40. Becke, A.D. J. Chem. Phys. 1993, 98, 5648. (b) Miehlich, B.; Savin, A.; Stoll, H.; Preuss, H. Chem. Phys. Lett. 1989, 157, 200.

41. Lee, C.; Yang, W.; Parr, R.G. Phys. Rev. B 1988, 37, 785.

42. Xu, W.; Peng, B.; Chen, J.; Liang, M.; Cai, F. J. Phys. Chem. C 2008, 112, 874.

43. Modelli, A.; Mussoni, L.; Fabbri, D. J. Phy. Chem. A 2006, 110, 6482. (b) Chang, Y. C.; Kuo, M. Y.; Chen, C. P.; Lu, H. F.; Chao, I. J. Phys. Chem. C 2010, 114, 11595.

44. Newman, C.R.; Frisbie, C.D.; da Silva, F.D.A.; Bredas, J.L.; Ewbank, P.C.; Mann, K.R. Chem. Mater. 2004, 16, 4436.

45. Usta, H.; Risko, C.; Wang, Z.; Huang, H.; Deliomeroglu, M.K.; Zhukhovitskiy, A.; Facchetti, A.; Marks, T.J. J. Am. Chem. Soc. 2009, 131, 5586.

46. Handa, S.; Miyazaki, E.; Takimiya, K. Chem. Commun. 2009, 3919.

47. Chen, H.Z.; Ling, M.M.; Mo, X.; Shi, M.M.; Wang, M.; Bao, Z. Chem. Mater. 2007, 19, 816. 